\title{
Letter to the editor regarding "Selective dorsal rhizotomy for spasticity of genetic etiology"
}

\author{
Mohit Agrawal $^{1} \cdot$ Kanwaljeet Garg $^{1}$ (I) $\cdot$ Shashwat Mishra ${ }^{1} \cdot$ Ramesh Doddamani $^{1} \cdot$ P. Sarat Chandra ${ }^{1}$
}

Received: 25 June 2020 / Accepted: 29 June 2020 / Published online: 2 July 2020

(C) Springer-Verlag GmbH Germany, part of Springer Nature 2020

\section{Dear Editor:}

We read with great interest the article by Lohkamp et al. [1] in which they reviewed the use of selective dorsal rhizotomy (SDR) for relief of spasticity secondary to genetic conditions such as hereditary spastic paraplegia.

Although it is a destructive procedure, there are several benefits of SDR over other available techniques of neuromodulation. No foreign implant is inserted in the body, which saves the patient from all its hardware-related complications, as well as the need for frequent hospital visits for programming. The high cost of such implants is another factor to be considered, especially in developing countries where the incidence of spasticity is high, while the resources to treat the same are sparse.

SDR has traditionally been used and continues to be used primarily for spasticity caused due to cerebral palsy in children. But awareness regarding its utility in relieving spasticity due to other indications is emerging [2]. We recently reviewed the available literature regarding the use of SDR for relief of spasticity in 57 patients, both pediatric and adult, following traumatic spinal and cranial injury [3]. The procedure has been used with generally good outcomes, which have been sustained even up until the longest available follow-up of 19 years. We further discussed the rationale behind the use of SDR for this indication, wherein surgery acts synergistically with physiotherapy to provide benefit to the patient. Given the otherwise global high costs of healthcare, there is a need to expand the indications for which this relatively low-cost technique can be effectively utilized.

Kanwaljeet Garg

kanwaljeet84@gmail.com

1 Department of Neurosurgery, All India Institute of Medical Sciences, New Delhi 110029, India
Considering this, we would like to applaud the authors for investigating the likely role of this procedure for another novel indication. Moreover, this article will increase the awareness about this procedure among the pediatric neurosurgeons. A recent editorial was published in this journal in which the author posed questions related to controversies in the field of rhizotomy to some of the most eminent functional neurosurgeons in the world [4]. The questions were related to the surgical procedure, outcome, and complications. We believe another question that needs to be asked to these experienced surgeons is, "How often do you use rhizotomy for indications other that cerebral palsy, and what are the outcomes observed from such procedures?" Further research on this topic can benefit many patients suffering with this potentially correctable source of disability.

\section{Compliance with ethical standards}

Conflicts of interest The authors declare that they have no conflict of interest.

\section{References}

1. Lohkamp LN, Coulter I, Ibrahim GM (2020) Selective dorsal rhizotomy for spasticity of genetic etiology. Childs Nerv Syst 36(7):13571365

2. Gump WC, Mutchnick IS, Moriarty TM (2013) Selective dorsal rhizotomy for spasticity not associated with cerebral palsy: reconsideration of surgical inclusion criteria. Neurosurg Focus 35:E6

3. Agrawal M, Samala R, Doddamani R, Agrawal D, Chandra SP (2020) The role of selective dorsal rhizotomy in the management of post-traumatic spasticity: systematic review [published online ahead of print, 2020 Feb 5]. Neurosurg Rev. https://doi.org/10. 1007/s10143-020-01255-w

4. Morota N (2020) What we have gained and what have remained controversial in the field of rhizotomy for spasticity since 2007 [published online ahead of print, 2020 Jan 28]. Childs Nerv Syst. https:// doi.org/10.1007/s00381-019-04487-4

Publisher's note Springer Nature remains neutral with regard to jurisdictional claims in published maps and institutional affiliations. 